\title{
Sustainable design of prefabricated solutions for the rehabilitation of ancient buildings
}

\author{
A. C. Coelho, J. M. Branco, P. B. Lourenço \\ ISISE, Dept. of Civil Engineering, University of Minho, Guimarães, Portugal \\ H. Gervásio \\ ISISE, Dept. of Civil Engineering, University of Coimbra, Coimbra, Portugal
}

\begin{abstract}
A wood-based "kit-of-parts" for the rehabilitation of existing buildings is under development. The aim is to merge the benefits of the standardized manufacture, with the flexibility needed to suit the specific requirements of the built heritage. The proposed system should be reversible, flexible and adaptable, while ensuring the adequate structural, thermal and acoustic performances. Mechanical joints, reversible if possible, should be used for the connections with the existing construction. Light solutions, allowing on site adjustment and future material separation are preferable.
\end{abstract}

\section{INTRODUCTION}

Intervention in ancient buildings aiming to preserve the heritage is highly challenger, with regard to the difficulty to understand the existing construction and to propose an adequate retrofit, in comparison with the design of a new building over a blank sheet. However, the rehabilitation needs will increase as the built heritage ages and the economic and social conditions will favour the return to the urban centres.

Rehabilitation and retrofit are currently major issues in the construction industry, focusing the attention of many researchers in an international level. The research motivations may vary among heritage preservation, economical concerns, environmental management or urban revitalization.

Sustainability issues in buildings were initially concerned with thermal efficiency, due to the long use phase, that represented the greatest share of energy consumption in the whole life cycle of the building. A great effort has been done in recent years to promote energy efficiency in buildings, with the increase in mandatory insulation of the outer shell, as well as the use of more efficient HVAC (Heating, Ventilation and Air Conditioning) systems. It is actually possible to design "zero energy buildings", or even buildings that are featured to produce energy, therefore having a positive energy balance. To keep improving the environmental profile of buildings after this achievement, the focus should now be shifted to the construction phase and the energy embodied in the construction materials and processes (Rossi et al., 2012).

\section{SUSTAINABILITY}

Sustainability may be assessed throughout three different perspectives, which should work in combination: the economical, the environmental and the social impacts.

\subsection{Rehabilitation}

Rehabilitation of ancient buildings certainly produces impacts in the three categories, being some of them more remarkable than the others.

On the economical point of view, the rehabilitation of ancient buildings in city centres may be important to the city's economical revitalization. On the other hand, in case the building presents an average good condition, its retrofit may be cheaper than the construction of a new one.

Concerning environmental issues, rehabilitation is a means of reuse existing structures, thus extending its materials life span. Reducing the demolition needs means limiting the residues production and also limiting the demand for new products.

On the social perspective, rehabilitation of ancient buildings may be analysed under two major highlights: the valorisation of a region and the creation of jobs due to the fact that working in ancient buildings, normally requires more man work than new building construction.

\subsection{Prefabrication and Standardization}

Abdallah (2007) argues that the use of prefabricated methods provides two main benefits for the construction industry: the first of them is the lower cost of the structures, with quality improvement over 
the life cycle; the second one is the improvement of the maintainability of the product, by means of an advanced manufacturing process, which balances present needs with long-term needs. Some other advantages of prefabrication also pointed by Abdallah (2007) are: the effectiveness of cost (first cost and life-cycle cost); earlier occupancy, reduced financing costs allowed by fast construction and the possibility of winter construction, avoiding weather delays. On the other hand, the same study refers to some special requirements of prefabricated methods: the additional effort on planning the work, comparing with on-site building methods; the additional engineering effort, in order to detail the prefabricated components and to develop construction sequences, optimizing the design; the need of specialized workmanship and equipment.

Prefabrication is actually an effective process on the improvement of the environmental performance of construction works, as well as on the promotion of self-construction.

\subsection{Wood}

Many centuries of wood-based construction made up a significant collection of wood building know-how, which preservation is important for local communities and may perform an important role in social sustainability issues.

When performing a life-cycle analysis (LCA) of wooden buildings, it is usually considered that trees store carbon dioxide in their tissues, which will only be released by the decay or combustion of wood. This wood feature is highlighted on long lifespan wood-based products, likewise most of the construction materials (Borjesson \& Gustavsson, 2000). In this discussion, Buchanan \& Levine (1999) point out that the ability of wood to store carbon is not significant when compared to the total carbon emissions of building products manufacturing. As all the wood products have a finite life, the carbon storage balance will remain constant over time, considering that the amount of wood in use will eventually reach a steady state. For those two reasons, the carbon storage of wood products cannot offset the manufacturing emissions in the long term. In any case, Buchanan \& Levine (1999) concludes that wood products require small amounts of energy in its manufacture, comparing with bricks, aluminium, steel and concrete. Therefore, when wood products are replacing energy-intensive ones, its lower embodied energy is significant towards the aim of carbon emission reduction in the long term, which is a permanent gain.

It can be assumed that the transformation process of wood produces virtually no waste, since all the wastage can be used for production of woodbased products or fuel, decreasing the demand for fossil fuels (Lippke et al., 2010, Sathre \& Gustavsson, 2009). Although wooden constructions will need maintenance throughout its lifetime, the traditional wooden building systems allows partial replacement of modules or damaged elements, without affecting the structure as a whole. The use of wood also contributes to the energy efficiency of buildings, since it is a material with low thermal conductivity (Branco, 2003) particularly when compared with steel.

When dismantling a wooden building, the recovered wood can be directly reused in another building or used as raw material for wood-based products, either by extending its useful life or simply used as biofuel, avoiding the need for fossil fuels.

\section{PREFABRICATION AND STANDARDIZATION IN REHABILITATION}

Based on the fact that large sets of buildings have been erected under a common architecture and constructive system, usually even using prefabricated elements (as far as prefabrication was developed back in the $18^{\text {th }}$ and $19^{\text {th }}$ centuries, as a consequence of the industrial revolution), that have been kept under similar conditions (environment and use), therefore presenting common pathologies, it becomes clear that the use of a prefabricated system for its rehabilitation is a suitable option. According to Teixeira \& Póvoas (2010), in the past centuries, the industrialization did not change the characteristics of the existing construction materials, but only increased its availability. Nowadays, it seems to be rational to use the same principle of increasing material availability and improving quality control on rehabilitation specific materials, which should present special features, necessarily different from the currently available new construction materials.

Assuming that, in these buildings, granite masonry structures usually present a good condition, being the timber elements more frequently damaged due to the lack of maintenance throughout several decades, the focus should be on repairing or replacing those elements. The slabs are suitable for prefabrication, due to the relatively regular span between structural supports (the gable masonry walls), provided that some adjustments may be executed on site, to offset any irregularities of the building. The choice of the material is critical to assure this on-site flexibility: wood plays an important role because it allows easy cut on-site. The interior partitions may be supplied with the right height (that is roughly repeated on these buildings), but some on-site adjustments in the extension of prefabricated boards may be required and should be enabled.

Concerning the roof, its main structure is made of timber trusses that are harder to prefabricate, due to its specific geometry and variety of shapes be- 
tween neighbours buildings. Nevertheless, there is still the chance to prefabricate the sheeting boards to apply over the trusses, providing the necessary thermal and acoustic insulation, as well as the base to apply the waterproofing membrane and the ceramic tiles.

\section{EXAMPLES OF AVAILABLE PRODUCTS}

There are some prefabricated wood structural products available on market, for example:

- ET slab and wall panel (Pequeno \& Cruz, 2009): is a composite panel, combining timber and glass; besides being structural, it also performs a thermal and an aesthetical function;

- Wenus slab and wall panel (www.cbs-cbt.com): was designed under the same principle of the corrugated cardboard, as a folded plate element with a "w" shape;

- O'portune slab (www.cbs-cbt.com): prefabricated slabs made with solid wood planks nailed or screwed together. There is the option to complement the slab with further layers to add finishing or to increase acoustic, thermal and fire resistance performance;

- Kielsteg slab (www.kielsteg.com): is a honeycomb slab, 100\% made of wood, designed to perform a high structural performance and to dismiss additional finishing;

\section{REQUIREMENTS TO FULFIL}

The system under development in the current research project should merge, in a single product, the concerns related with sustainability and the concerns related to old-building rehabilitation. Some general requirements were defined.

\subsection{General requirements}

According to Couto et al. (2006), some of the recommendations in order to promote recycling in construction are: the use of recycled materials, to help the development of this market segment; the minimization of different types of materials on the same element; the avoidance of toxic and hazardous materials; the allowance of future separation of different recycling-potential materials; the avoidance of secondary finishing; the permanent identification of the different materials in use; the minimization of different parts on the same element; the use of mechanical connections, or, when necessary, chemical connections weaker than the connected parts, enabling future separation; the design of easy-handling parts; the design with realistic tolerances, allowing necessary movements in assembling and disassembling operations; the limit of different connectors, to allow disassembling with minimum different tools; and also the design taking account of disassembling order, related to the expected lifespan of components, assuring easier access to less durable parts.

The size of the components is also a major issue, considering the need to deliver the parts into the right place in the building (most of the times keeping the masonry envelope of the building), as well as the practicability of the dismantling process at the endof-life.

\subsection{Ventilation}

Timber needs ventilation in order to increase its useful lifetime. In the specific case of masonry buildings, ventilation is particularly important in the connection between timber and stone, due to the probability that stone presents some capillarity moisture, arising from its contact with the soil.

Also the roof should be carefully designed in order to avoid any moisture to get into the building, while allowing the necessary ventilation.

\section{PROPOSAL DESIGN}

In the first phase of the research project, a prefabricated slab was proposed, according to Figure 1.

It respects the same principles of the traditional Portuguese timber structures, starting with structural beams that cover the span between masonry gable walls, which may vary between 5 and 7 meters, depending on the age of the building. On the $18^{\text {th }}$ century buildings, the spans were around 5 or 6 meters, arising to 7 meters in the $19^{\text {th }}$ century. Nevertheless, in order to suit the needs of the vast majority of the buildings, avoiding the need to manufacture a special product, a span up to 7,5 meters is considered by default. As long as the slab's composition is the same over its entire area (considering a transversal section), the slab may be cropped on site, to fit the desired geometry of the building. For this reason, all the materials in use are timber and wood products, to allow workability with simple tools. The only exception is the waterproofing membrane.

The solid wood beams are sheeted in both faces by OSB panels. In order to avoid any waste of material, the OSB standard size of $2500 \times 1250 \times 22 \mathrm{~mm}$ is fully used. Therefore, each panel's width is $1250 \mathrm{~mm}$ and its length vary in multiples of $2500 \mathrm{~mm}$, so that the slabs may be manufactured with the span length of 5 or 7.5 meters, to suit the needs of smaller (and older) buildings, as well as the needs of more recent and bigger ones. In any case, it is assured that an existing timber floor-structure may always be replaced by this system, because the traditional span allowed by the use of timber is never higher than 7.5 meters.

Above the OSB up layer, there is a cork layer (25 $\mathrm{mm}$ thickness), to assure the necessary acoustic performance, both for air and percussion noise. The floor finishing is made with a solid wood flooring 
with $20 \mathrm{~mm}$ thickness, likewise the traditional flooring used in this kind of building (figure 2).

Below the timber beams, there is also an OSB layer (22 $\mathrm{mm}$ thickness), coated on the bottom side with a waterproofing membrane, to assure the sealing between floors. The prefabricated slabs are supplied with the standard width of $1.25 \mathrm{~mm}$, to allow easy handling on site. The slab has an indentation, in order to perfectly associate it with the contiguous parts, assuring the visual continuity. For continuity reasons, both the top and bottom finishes follow a stereotomy that is parallel to the structure and to the assembling direction (figure 2).

The finishing of the bottom side of the slab, which corresponds to the ceiling of the floor below, is made of solid wood slats, designed to assure the continuity of the ceiling, dismissing the need to a on site additional finishing process (figure 2).

The first and last prefabricated slab to apply in each floor is likely to have a special geometry, in order to fit with a third masonry wall (the front and the back facade). Anticipating this issue, a special slab was designed, replacing the solid wood beams by a solid structural layer of solid wood, made of several solid wood beams joined together (figure 3). This assures that this slab may be cropped in any shape and size, keeping its structural behaviour, specially in case the necessary area to cover demands a slab which width is less than the regular spacing of 565 $\mathrm{mm}$ between structural solid wood beams.

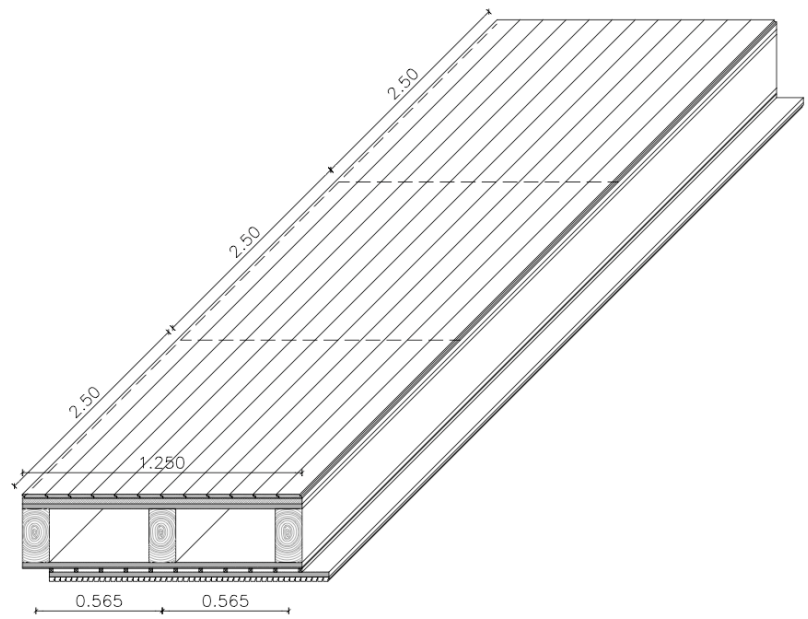

Figure 1 - General prefabricated slab

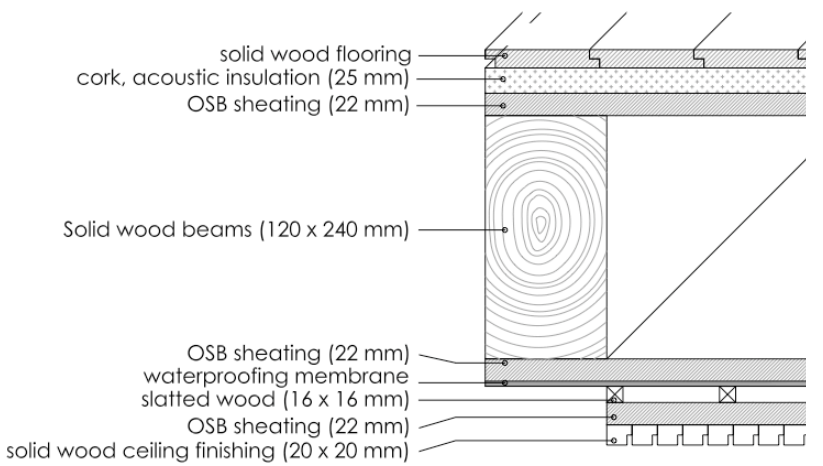

Figure 2 - General prefabricated slab detail, transversal section

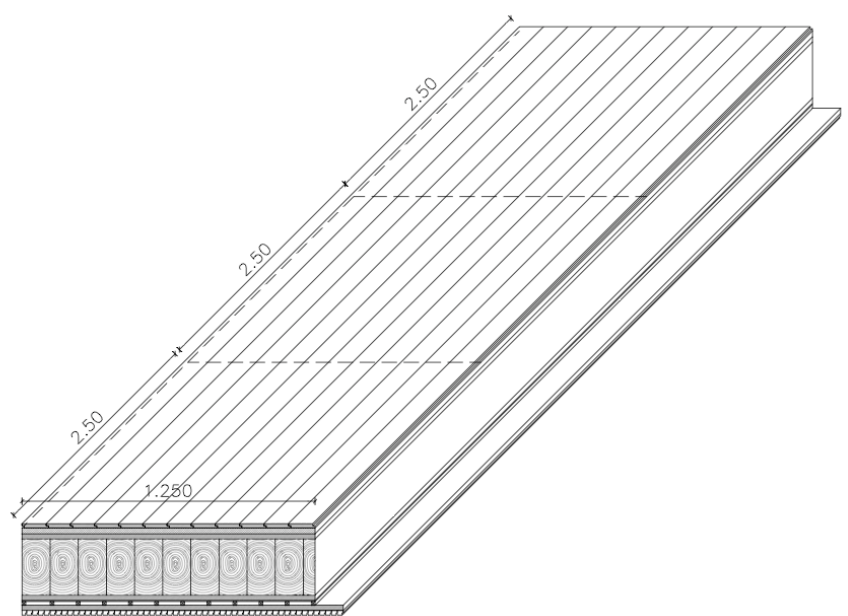

Figure 3 - Special slab to be used in the tops

The on site assembling should start with the fixing of a continuous steel L shaped profile to the gable masonry walls that will support the slab's loads (figure 4, step 1). The prefabricated slab is supplied in two parts, to enable the assembling process. The top part (structure, acoustic insulation, waterproofing and floor finishing) should stand directly over the steel perimeter beam, allowing some geometric tolerance (figure 4, step 2) that will be later offset by the addition of wall panels to improve the performance of the external walls. At last, the bottom part (ceiling finishing) should be screwed to the slatted wood on the top part, that is designed in such a way that the steel beam keeps hidden inside the slab (figure 4, step 3). The final section is shown on Figure 5.

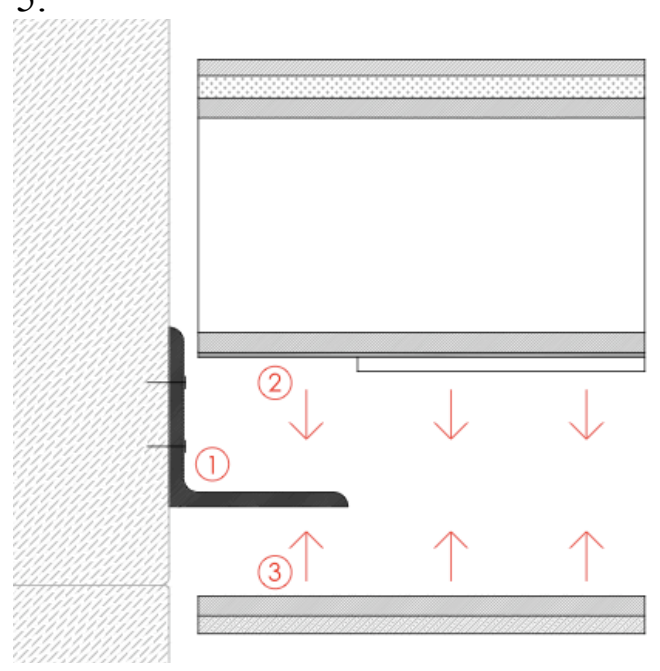

Figure 4 - Assembling order 


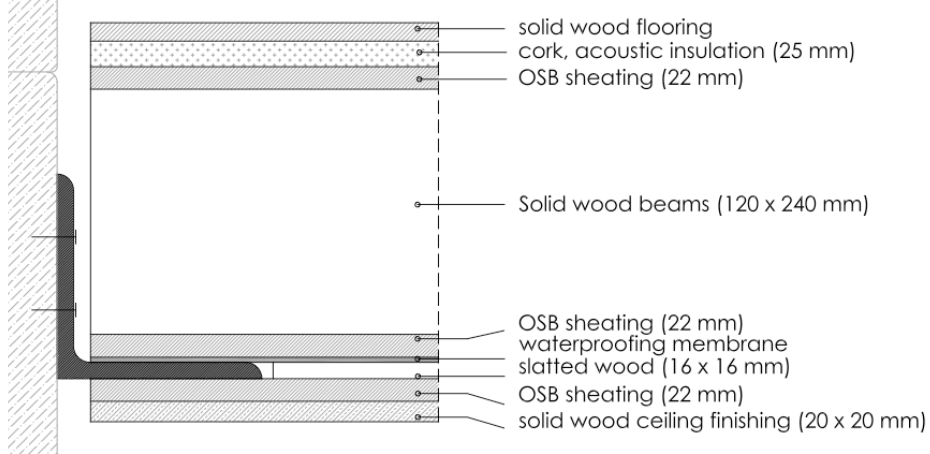

Figure 5 - Detail after assembling, connection to the masonry wall

\section{CONCLUSIONS AND FURTHER DEVELOPMENTS}

It has been discussed in this paper that there are some actual opportunities to develop an existing building intervention strategy that makes it cheaper, faster, safer and more reliable than the current processes. One of the avenues in order to achieve these goals may be the introduction of prefabricated products and systems, specially featured for the use in the rehabilitation of existing buildings. Nevertheless, the use of a prefabricated system is only possible to apply in case the building is not protected heritage, when new elements may be a suitable option to replace its damaged parts. The starting research presented in this paper aims to propose prefabricated and industrialized wood-based systems for the intervention in existing buildings in Portugal. The solutions, inspired and respectful to the traditional materials and techniques, aimed to be fully compatible with the existing structures and materials. Despite the local characteristics and requirements, it is believed that those construction systems can be used in the traditional buildings of different European countries.

In this paper, a wood-based slab has been proposed. The further development of the slab design includes its economical and sustainable optimization, as well as its real scale prototype and testing.

The research project includes the development of some other parts to be used in the same sort of projects, mainly a versatile wall, that should fulfil the requirements for an interior partition or the upgrade of the external walls thermal performance, being attached to their internal face.

In order to fully assess the sustainability of the proposed system, in comparison to the current means of intervention on these buildings, a detailed LCA (Life cycle assessment) of all the proposed prefabricated products will be performed and published, to allow the environmental labelling of each product. The aim of labelling each product is the inclusion of sustainability criteria early in the project phase, allowing architects and engineers to make the project options based not only in economical and structural performance of products, but from now on including the environmental and social performance as well, for a complete sustainability characterization.

\section{ACKNOWLEDGEMENT}

The research project presented in this paper is part of "WoodenQuark n. ${ }^{\circ}$ 2011/21635" from the Portuguese financing programme "Quadro de Referência Estratégico Nacional".

The authors also acknowledge the cooperation of "SRU - Sociedade de Reabilitação Urbana do Porto Vivo".

\section{REFERENCES}

Abdallah, A. (2007). Managerial and economic optimizations for prefabricated building systems. Technological and Economic Development of Economy (13:1), 83-91.

Borjesson, P., \& Gustavsson, L. (2000). Greenhouse gas balances in building construction: wood versus concrete from life-cycle and forest land-use perspectives. Energy Policy (28), 575-588.

Branco, J. (2003). Comportamento das ligações tipo cavilha em estruturas mistas madeira-betão. Guimarães: Dissertação apresentada à Universidade do Minho para obtenção de grau de Mestre em Engenharia Civil, Especialização em Estruturas, Geotecnia e Fundações. (in Portuguese)

Buchanan, A., Levine, S. (1999). Wood Based Building Materials and Atmospheric Carbon Emissions. In: Environmental Science \& Policy, 2, pp. 427-437.

CBS-CBT, Engineering, Technology, Timber construction website "www.cbs-cbt.com", last visited on $1^{\text {st }}$ March 2013

Couto, A., Couto, J., \& Teixeira, J. (2006). Desconstrução Uma ferramenta para sustentabilidade da construção. NUTAU 2006. (in Portuguese)

Kielsteg Bauelemente, innovative smart wood structures - website "www.kielsteg.com", last visited on $1^{\text {st }}$ March 2013

Lippke, B., Wilson, J., Meil, J., \& Taylor, A. (2010). Characterizing the importance of carbon stored in wood products. Wood and Fiber Science (42, Corrim Special Issue), 5-14.

Rossi, B., Marique, A.-F., Glaumann, M., \& Reiter, S. (2012). Life-cycle assessment of residential buildings in three different European locations, basic tool. Building and Environment (51), 395-401.

Sathre, R., \& Gustavsson, L. (2009). Using wood products to mitigate climate changes: External costs and structural change. Applied Energy (89), 251-257.

Teixeira, J., \& Póvoas, R. (2010). Proposta de metodologia de intervenção para a reabilitação do património urbano edificado - as casas burguesas do Porto, coberturas. Reabilitar 2010 - Encontro Nacional Conservação e Reabilitação de Estruturas, 1-11 (in Portuguese) 